\title{
The prostate health index PHI predicts oncological outcome and biochemical recurrence after radical prostatectomy - analysis in 437 patients
}

\author{
Andreas Maxeiner ${ }^{1}$, Ergin Kilic ${ }^{2}$, Julia Matalon ${ }^{1}$, Frank Friedersdorff ${ }^{1}$, Kurt Miller ${ }^{1}$, \\ Klaus Jung ${ }^{1,3}$, Carsten Stephan ${ }^{1,3}$ and Jonas Busch ${ }^{1}$ \\ ${ }^{1}$ Department of Urology, Charité, Universitaetsmedizin Berlin, Berlin, Germany \\ 2 Department of Pathology, Charité, Universitaetsmedizin Berlin, Berlin, Germany \\ ${ }^{3}$ Berlin Institute for Urologic Research, Berlin, Germany \\ Correspondence to: Andreas Maxeiner, email: andreas.maxeiner@charite.de \\ Keywords: prostate cancer; biomarker; prostate health index; prostate-specific antigen; biochemical recurrence \\ Received: January 30, $2017 \quad$ Accepted:April 15, $2017 \quad$ Published: April 27, 2017
}

Copyright: Maxeiner et al. This is an open-access article distributed under the terms of the Creative Commons Attribution License 3.0 (CC BY 3.0), which permits unrestricted use, distribution, and reproduction in any medium, provided the original author and source are credited.

\section{ABSTRACT}

The purpose of this study was to investigate the Prostate-Health-Index (PHI) for pathological outcome prediction following radical prostatectomy and also for biochemical recurrence prediction in comparison to established parameters such as Gleason-score, pathological tumor stage, resection status (RO/1) and prostatespecific antigen (PSA).

Out of a cohort of 460 cases with preoperative PHI-measurements (World Health Organization calibration: Beckman Coulter Access-2-Immunoassay) between 2001 and 2014, 437 patients with complete follow up data were included. From these 437 patients, 87 (19.9\%) developed a biochemical recurrence. Patient characteristics were compared by using chi-square test. Predictors were analyzed by multivariate adjusted logistic and Cox regression.

The median follow up for a biochemical recurrence was 65 (range 3-161) months. PHI, PSA, [-2]proPSA, PHI- and PSA-density performed as significant variables ( $p$ $<0.05$ ) for cancer aggressiveness: Gleason-score $<7$ or $\geq 7$ (ISUP grade 1 or $\geq 2$ ). Concerning pathological tumor stage discrimination and prediction, variables as $\mathrm{PHI}$, PSA, \%fPSA, [-2]proPSA, PHI- and PSA-density significantly discriminated between stages <pT3 and $\geq \mathrm{pT} 3$ with the highest AUC (0.7) for PHI. In biochemical recurrence prediction PHI, PSA, [-2]proPSA, PHI- and PSA-density were the strongest predictors.

In conclusion, due to heterogeneity of time spans to biochemical recurrence, longer follow up periods are crucial. This study with a median follow up of more than 5 years, confirmed a clinical value for PHI as an independent biomarker essential for biochemical recurrence prediction.

\section{INTRODUCTION}

Prostate-specific antigen (PSA) has been established within the last 30 years for prostate cancer $(\mathrm{PCa})$ management and the detection of its molecular forms including free PSA (fPSA) in the early 1990s $[1,2]$ enhanced specificity [3]. A PPSA subform named proPSA [4] has proved to be the most cancer-specific PSA form $[5,6]$. First data using an in-house assay specific for [-2]
proPSA already indicated an association between tumor aggressiveness and this new marker $[7,8]$.

The introduction of a commercially available [-2] proPSA assay $[9,10]$ and especially the combined formula

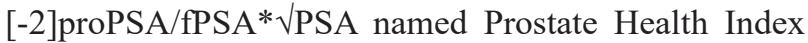
(PHI) in 2010 led to clinical improved PCa detection [11, 12]. Numerous multicenter studies in biopsied patients proved that PHI preferentially detects aggressive $\mathrm{PCa}$ [1316]. The FDA approved PHI in 2012 as a biopsy indicator in men with a PSA of 4 to $10 \mathrm{ng} / \mathrm{ml}$ and a negative digital 
rectal examination. A meta-analysis in biopsied men with a PSA of 2 to $10 \mathrm{ng} / \mathrm{ml}$ showed a superiority of PHI compared to PSA and percent fPSA (\%fPSA) [17].

A prospective study in 350 men who underwent radical prostatectomy (RP) found $\mathrm{PHI}$ to be an accurate predictor of pT3 disease, a pathologic Gleason score $\geq$ 7 (International Society of Urological Pathology (ISUP) grade $\geq 2$ ) and Gleason score upgrading [18]. A recent multicenter study in almost 500 PCa patients with RP indicated a significant accuracy increase in multivariable models by $2.3 \%$ and $2.4 \%$ for the prediction of pT3 disease and/or pathologic Gleason score $\geq 7$ (ISUP grade $\geq 2$ ) by inclusion of PHI, respectively [19]. Consequently, PHI as a confirmed diagnostic tool could be used as a prediction and also as a prognostic tool. To predict the prognosis accurately with focus on cancer control a first indicator is a biochemical recurrence (BCR) defined as PSA increase from zero to $0.2 \mathrm{ng} / \mathrm{ml}$. Further indicators such as metastatic progression or cancer-specific and overall mortality may appear much later than a BCR or may be more important in primary metastatic PCa. However, there is no doubt about the need for a better outcome prediction according to expert opinions [20]. Recommendations regarding adjuvant radiation therapy and/or hormonal treatment after RP, are mainly based on pathological stage (pT2 or pT3), resection status (R0 or R1) and lymph node invasion (pN0 or pN1) [21, 22]. Additional tools including biomarkers [23] for a better evaluation of further therapies could lead to a more individual treatment strategy. This could lead to lower rates of postoperative overtreatment or stronger indications for direct adjuvant postoperative treatment despite an optimal PSA nadir of $<0.01 \mathrm{ng} / \mathrm{ml}$.

While our survey was finished, a very recent study already investigated PHI as a prognostic marker for early BCR [24]. This single center study in 313 RP patients had a short median follow up of 28 months and included only 34 patients with BCR (10.9\%). Using an atypical high PHI cutoff of 82, the BCR-free survival rates were $97.7 \%$ in those patients below and only $69.7 \%$ above this PHI cutoff. However, PHI was an independent predictor of a BCR. In univariate analysis the categorical PHI (cutoff 82) with an area under (AUC) the Receiver Operating Characteristic (ROC) curve of $66.4 \%$ was somewhat more accurate than stage (pT3 vs. pT2, AUC $66.3 \%$ ), tumor volume (AUC 65.7\%), pathological Gleason score $\geq 7 v s . \leq 6$ (ISUP grade $\geq 2 v s 1)$, (AUC $65.5 \%$ ), surgical margin (resection) status (R1 vs. R0, AUC 64.6\%) or PSA (AUC 60.1\%) [24]. Similarly, a multivariable model that included the categorically coded PHI showed the highest AUC with $71.2 \%$ compared to the models based on continuously coded PHI levels (AUC $67.9 \%$ ) or PSA (AUC 67.3\% $P<0.001$ ) [24]. However, Lughezzani et al. [24] concluded that external validation in larger populations with longer follow up is needed. Our present study provides information in compliance with this request. The aim of our study was 1) to investigate the predictive power of PHI in comparison with other biomarkers and 2) to compare this serum marker with the established parameters such as Gleason score, stage, margin status or PSA based on longer follow up data for BCR prediction in preoperative and postoperative settings.

\section{RESULTS}

\section{ROC analysis of PHI}

Patient characteristics are displayed within Table 1. During a median follow up of 65 months (range 3-161

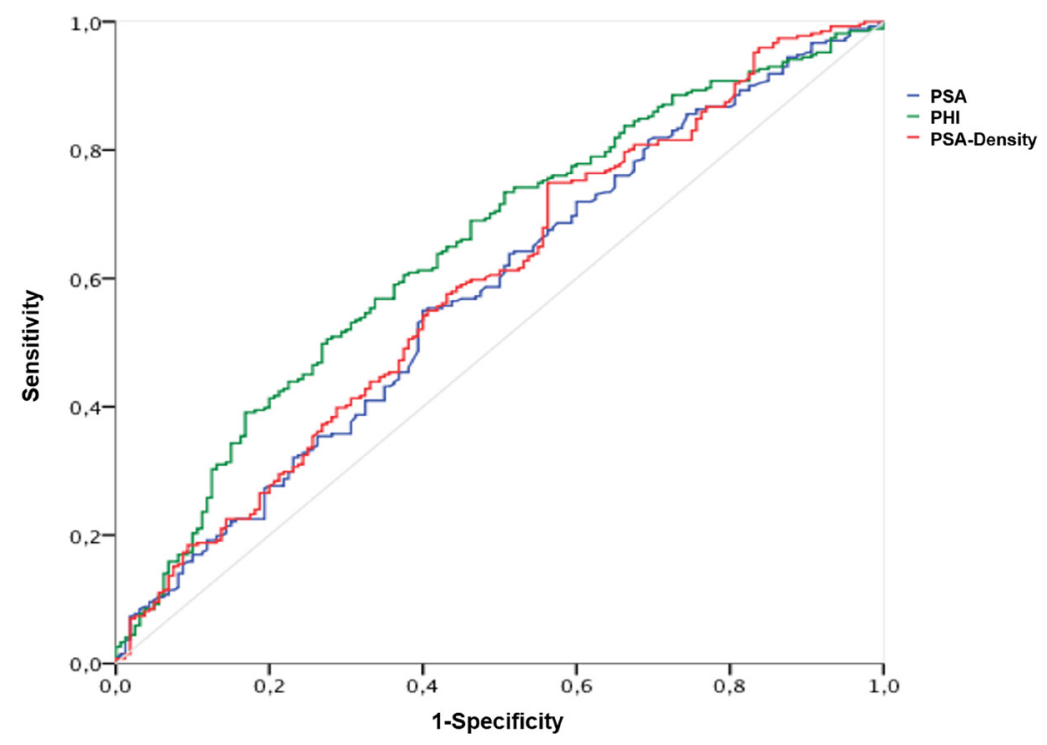

Figure 1: Prediction of postoperative Gleason Score $(<7$ and $\geq 7)$. Abbreviations: PSA - prostate-specific antigen; fPSA - free PSA; PHI - Prostate Health Index. 
Table 1: Patient characteristics

\begin{tabular}{|l|c|l|l|l|}
\hline Variable & $\begin{array}{l}\text { Included patients } \\
\mathbf{N = 4 3 7}\end{array}$ & $\begin{array}{l}\text { BCR } \\
\mathbf{N = 8 7}\end{array}$ & $\begin{array}{l}\text { No BCR } \\
\mathbf{N}=\mathbf{3 5 0}\end{array}$ & $\left.\left.\begin{array}{l}\boldsymbol{P} \text {-value } \\
*\end{array}\right) * *\right)$ \\
\hline $\begin{array}{l}\text { Age, years } \\
\text { Median (Range) }\end{array}$ & $63(44-78)$ & $64.0(44.0-75.0)$ & $63(45.0-78.0)$ & 0.211 \\
\hline $\begin{array}{l}\text { PSA, ng/mL } \\
\text { Median (Range) }\end{array}$ & $4.71(0.25-66.5)$ & $5.14(1.46-66.5)$ & $4.49(0.00-33.8)$ & 0.092 \\
\hline $\begin{array}{l}\text { fPSA ng/ml } \\
\text { Median (Range) }\end{array}$ & $0.58(0.02-10.6)$ & $0.62(0.00-3.70)$ & $0,58(0.00-10.6)$ & 0.313 \\
\hline $\begin{array}{l}\text { \%fPSA/ Ratio } \\
\text { Median (Range) }\end{array}$ & $14.1(3.96-198)$ & $11.7(3.97-108)$ & $14,5(4.35-198)$ & 0.064 \\
\hline $\begin{array}{l}\text { [-2]proPSA pg/ml } \\
\text { Median (Range) }\end{array}$ & $12.1(0.64-108)$ & $14.4(2.80-66.9)$ & $11.8(0.64-108)$ & 0.043 \\
\hline $\begin{array}{l}\text { \%[-2]proPSA } \\
\text { Median (Range) }\end{array}$ & $261(53.7-1104)$ & $237(75.2-956)$ & $266(53.7-1105)$ & 0.312 \\
\hline $\begin{array}{l}\text { PHI continous } \\
\text { Median (Range) }\end{array}$ & $46.4(7.79-450)$ & $58.6(8.17-246)$ & $44.5(7.79-450)$ & $<0.001$ \\
\hline $\begin{array}{l}\text { TRUS, mL } \\
\text { Median (Range) }\end{array}$ & $35(12-120)$ & $33.0(13-114)$ & $35.0(12.0-120)$ & 0.381 \\
\hline $\begin{array}{l}\text { PSA density } \\
\text { Median (Range) }\end{array}$ & $0.13(0.01-1.52)$ & $0.16(0.36-1.33)$ & $0.12(0.01-1.52)$ & $<0.001$ \\
\hline $\begin{array}{l}\text { PHI density } \\
\text { Median (Range) }\end{array}$ & $1.33(0.16-9.38)$ & $1.61(0.16-9.03)$ & $1.29(0.24-9.38)$ & $<0.001$ \\
\hline
\end{tabular}

Abbreviations: BCR - biochemical recurrence; CI - confidence interval; PSA - prostate-specific antigen; TRUS - transrectal ultrasound; PHI - prostate health index; (*The p-value refers to Fisher's exact (Chi-square) test for categorical variables; **The $\mathrm{p}$-value refers to Mann Whitney $\mathrm{U}$ test for continuous variables).

months) a BCR was observed in $87(19.9 \%)$ out of 437 included patients. The rate of positive surgical margins (R1) was $26.3 \%$ (115) overall, including 40 from 87 cases that developed a BCR. Preoperative risk stratification was performed after d'Amico with 161 (36.8\%) low-risk, 219 (50.1\%) intermediate-risk and 57 (13.1\%) high-risk cases, respectively. Preoperative median PSA was $4.71 \mathrm{ng} / \mathrm{ml}$ (range: $0.25-66.5$ ) and according to d'Amico: $<10 \mathrm{ng} / \mathrm{ml}$ in $390(89.2 \%)$ cases, $>10 \mathrm{ng} / \mathrm{ml}$ in $36(8.3 \%)$ cases and $>$ $20 \mathrm{ng} / \mathrm{ml}$ in $11(2.5 \%)$ cases.

The AUC calculations for differentiation between Gleason score $<7$ and $\geq 7$ (ISUP grade 1 and $\geq 2$ ) are

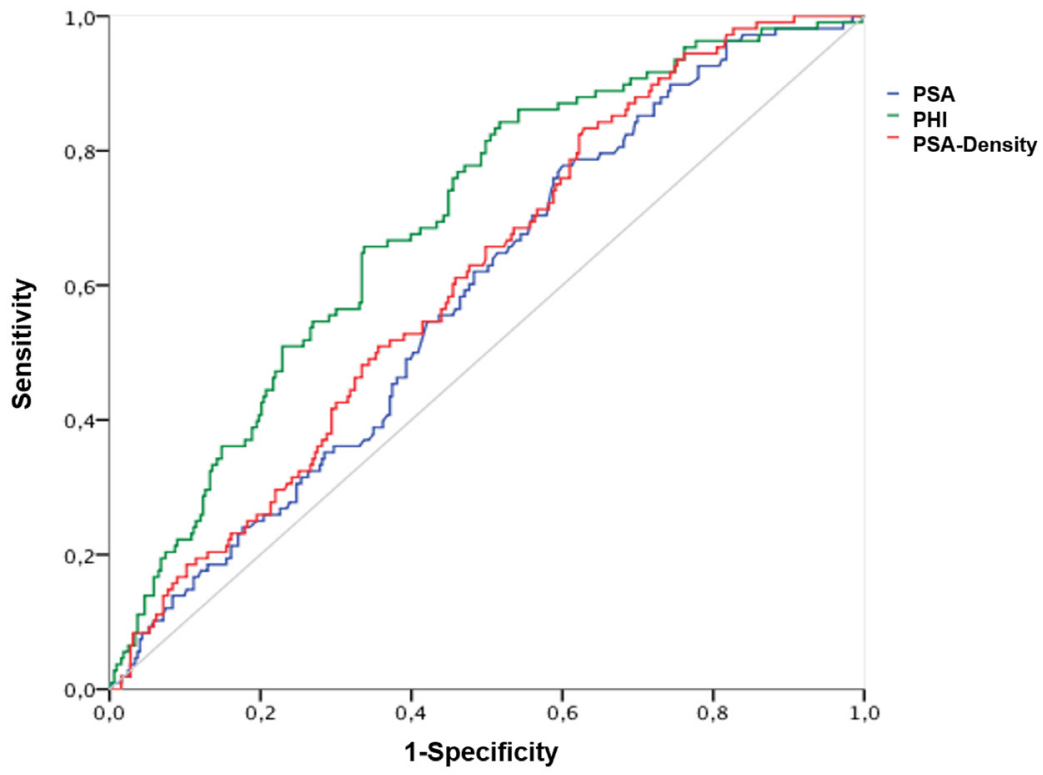

Figure 2: Prediction of pathological tumor stages ( < pT3 and $\geq$ pT3). Abbreviations: PSA - Prostate specific antigen; fPSA - free PSA; PHI - Prostate Health Index. 
Table 2: Predicitive power analysis

\begin{tabular}{|c|c|c|c|c|c|c|c|c|c|}
\hline & Results & $\overline{\text { PSA }}$ & fPSA & PHI & $\begin{array}{c}{[-2]} \\
\text { proPSA }\end{array}$ & $\begin{array}{c}\text { PSA- } \\
\text { density }\end{array}$ & $\begin{array}{c}\text { PHI- } \\
\text { density }\end{array}$ & \%fPSA & $\begin{array}{c}\%[-2] \\
\text { proPSA }\end{array}$ \\
\hline $\begin{array}{c}\text { Gleason } \\
\text { Score } \\
<7 / \geq 7\end{array}$ & $\begin{array}{c}\text { AUC } \\
(95 \% \\
\text { CI })\end{array}$ & $\begin{array}{c}0.577 \\
(0.521- \\
0.633)\end{array}$ & $\begin{array}{c}0.528 \\
(0.472- \\
0.584)\end{array}$ & $\begin{array}{c}0.647 \\
(0.593- \\
0.700)\end{array}$ & $\begin{array}{c}0.597 \\
(0.543- \\
0.651)\end{array}$ & $\begin{array}{c}0.592 \\
(0.536- \\
0.647)\end{array}$ & $\begin{array}{c}0.616 \\
(0.561- \\
0.670)\end{array}$ & $\begin{array}{c}0.495 \\
(0.440- \\
0.551)\end{array}$ & $\begin{array}{c}0.503 \\
(0.447- \\
0.559)\end{array}$ \\
\hline $\begin{array}{l}\text { (ISUP } \\
\text { grade } \\
1 / \geq 2 \text { ) }\end{array}$ & p-value & 0.007 & 0,333 & $<0,001$ & 0.001 & 0.001 & $<0,001$ & 0.867 & 0.916 \\
\hline \multirow[t]{2}{*}{$\begin{array}{c}<\mathrm{pT3} \\
\text { and } \\
\geq \mathrm{pT} 3\end{array}$} & $\begin{array}{c}\text { AUC } \\
(95 \% \\
\text { CI })\end{array}$ & $\begin{array}{l}0.586( \\
0.527- \\
0.644)\end{array}$ & $\begin{array}{c}0.518 \\
(0.453- \\
0.583)\end{array}$ & $\begin{array}{c}0.695 \\
(0.640- \\
0.749)\end{array}$ & $\begin{array}{c}0.612 \\
(0.549- \\
0.675)\end{array}$ & $\begin{array}{c}0.611 \\
(0.554- \\
0.668)\end{array}$ & $\begin{array}{c}0.670 \\
(0.613- \\
0.727)\end{array}$ & $\begin{array}{c}0.578 \\
(0.358- \\
0.486)\end{array}$ & $\begin{array}{r}0.527 \\
(0.466- \\
0.589)\end{array}$ \\
\hline & $p$-value & 0.007 & 0.574 & $<0,001$ & $<0,001$ & 0.001 & $<0,001$ & 0.015 & 0.399 \\
\hline \multirow[t]{2}{*}{$\begin{array}{c}\text { BCR } \\
\text { YES / } \\
\text { NO }\end{array}$} & $\begin{array}{c}\text { AUC } \\
(95 \% \\
\text { CI })\end{array}$ & $\begin{array}{c}0.591 \\
(0.528- \\
0.653)\end{array}$ & $\begin{array}{c}0.536 \\
(0.470- \\
0.603)\end{array}$ & $\begin{array}{c}0.623 \\
(0.559- \\
0.688)\end{array}$ & $\begin{array}{c}0.573 \\
(0.504- \\
0.641)\end{array}$ & $\begin{array}{c}0.612 \\
(0.548- \\
0.676)\end{array}$ & $\begin{array}{c}0.607 \\
(0.540- \\
0.673)\end{array}$ & $\begin{array}{c}0.564 \\
(0.367- \\
0.505)\end{array}$ & $\begin{array}{r}0.037 \\
(0.395- \\
0.540)\end{array}$ \\
\hline & $p$-value & 0.009 & 0.293 & $<0,001$ & 0.036 & 0.001 & 0.002 & 0.064 & 0.345 \\
\hline
\end{tabular}

Abbreviations: AUC - area under the curve; PSA - prostate-specific antigen; fPSA - free PSA; PHI - prostate health index; pT - pathological tumor stage; BCR - biochemical recurrence; CI - confidence interval;

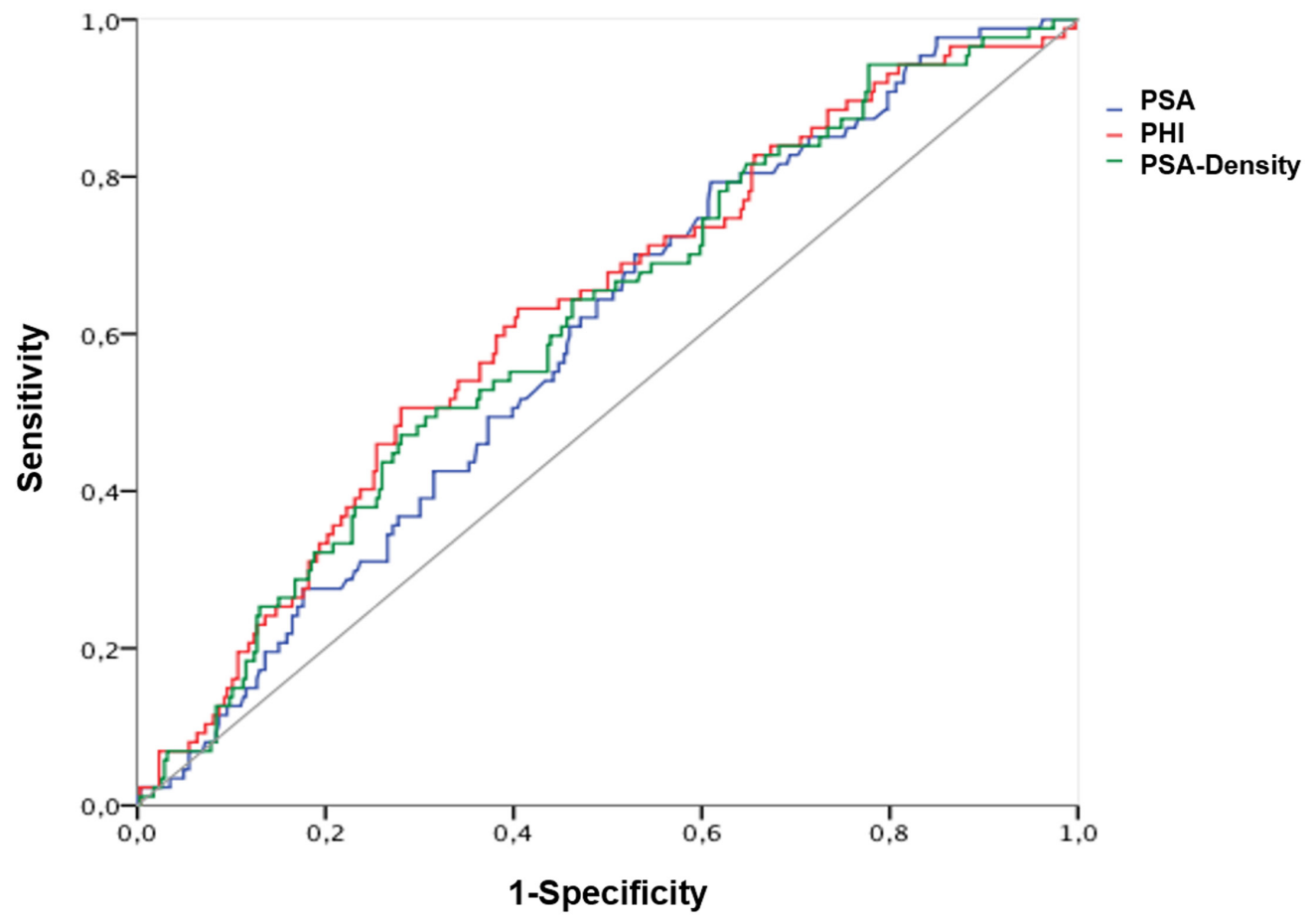

Figure 3: Prediction of biochemical recurrence after radical prostatectomy. Abbreviations: PSA - Prostate-specific antigen; fPSA - free PSA; PHI - Prostate Health Index. 
Table 3: Univariate and multivariable logistic regression model of preoperative variables predicting pathological stage >pT2 following radical prostatectomy

\begin{tabular}{|l|c|c|c|c|c|c|}
\hline \multirow{2}{*}{ Variable } & \multicolumn{3}{|c|}{ Univariate analyses } & \multicolumn{3}{c|}{ Multivariable analyses } \\
\cline { 2 - 7 } & OR & $\mathbf{9 5 \%}$ CI & $\boldsymbol{p}$-value & OR & $\mathbf{9 5 \%}$ CI & $\boldsymbol{p}$-value \\
\hline PSA, ng/mL (continuous) & 1.04 & $0.99-1.09$ & 0.070 & $\mathrm{n} / \mathrm{a}$ & & \\
\hline PHI (continuous) & 1.02 & $1.01-1.03$ & $<0.00001$ & $\mathrm{n} / \mathrm{a}$ & & \\
\hline PHI & & & & & & \\
>median vs <median & 2.86 & $1.80-4.53$ & $<0.00001$ & 2.20 & $1.36-3.57$ & 0.001 \\
\hline TRUS volume, ml & 0.99 & $0.98-1.00$ & 0.121 & $\mathrm{n} / \mathrm{a}$ & & \\
\hline Age, years (continuous) & 1.02 & $0.99-1.06$ & 0.18 & $\mathrm{n} / \mathrm{a}$ & & \\
\hline Biopsy Gleason Score & & & & & & \\
<7 (ISUP grade 1) & Ref & & & Ref. & & \\
=7 (ISUP grade 2 and 3) & 4.11 & $2.24-7.53$ & $<0.0001$ & 3.65 & $1.97-6.73$ & $<0.00001$ \\
$>7$ (ISUP grade $\geq 4$ ) & 10.86 & $5.13-22.99$ & $<0.0001$ & 8.76 & $4.08-18.82$ & $<0.00001$ \\
\hline
\end{tabular}

Abbreviations: PSA - prostate-specific antigen; PHI - prostate health index; pT - pathological tumor stage; TRUS - transrectal ultrasound; CI - confidence interval; OR - odds ratio; CI - confidence interval.

Table 4: Univariate and multivariable logistic regression model of preoperative variables predicting pathological Gleason Score $>6$ following radical prostatectomy

\begin{tabular}{|l|c|c|c|c|c|c|}
\hline \multirow{2}{*}{ Variable } & \multicolumn{3}{|c|}{ Univariate analyses } & \multicolumn{3}{c|}{ Multivariable analyses } \\
\cline { 2 - 7 } & OR & $\mathbf{9 5 \%}$ CI & $\boldsymbol{p}$-value & OR & $\mathbf{9 5 \%}$ CI & $\boldsymbol{p}$-value \\
\hline PSA, ng/mL (continuous) & 1.07 & $1.01-1.13$ & 0.015 & $\mathrm{n} / \mathrm{a}$ & & \\
\hline PHI (continuous) & 1.02 & $1.01-1.03$ & 0.00002 & $\mathrm{n} / \mathrm{a}$ & & \\
\hline $\begin{array}{l}\text { PHI } \\
>\text { median vs }<\text { median }\end{array}$ & 2.46 & $1.64-3.67$ & $<0.0001$ & 2.09 & $1.35-3.24$ & 0.001 \\
\hline $\begin{array}{l}\text { Clinical stage } \\
\geq \text { cT2 vs cT1 }\end{array}$ & 1.95 & $1.12-3.16$ & 0.006 & 1.82 & $1.11-2.96$ & 0.017 \\
\hline Age, yrs (continuous) & 1.014 & $0.99-1.05$ & 0.341 & $\mathrm{n} / \mathrm{a}$ & & \\
\hline TRUS volume, ml & 0.997 & $0.99-1.01$ & 0.570 & $\mathrm{n} / \mathrm{a}$ & & \\
\hline
\end{tabular}

Abbreviations: PSA - prostate-specific antigen; PHI - prostate health index; pT - pathological tumor stage; TRUS - transrectal ultrasound; CI - confidence interval; OR - odds ratio; CI - confidence interval.

shown in Table 2 with the corresponding ROC curves displayed within Figure 1, respectively. A Gleason score $>$ 7 (ISUP grade $\geq 4$ ) was found in $161(36.8 \%)$; $=7$ (ISUP grade 2 and 3 ) in $220(50.1 \%)$ and $<7$ (ISUP grade 1) in $56(12.8 \%)$ patients. Hence, according to aggressiveness (Gleason score $<7$ and $\geq 7$ ) (ISUP grade 1 and $\geq 2$ ) PHI, PSA and further [-2]proPSA, PHI- and PSA-density could be identified as significant variables. Contrarily, fPSA with an AUC of 0.528 and \%fPSA with an AUC of 0.495 showed no improvement of prediction in comparison to PSA (AUC 0.577). Similarly, [-2]proPSA (AUC 0.597) and \% [-2]proPSA (AUC 0.50) showed no additional improvement in contrast to PHI (AUC 0.647). Therefore, fPSA, \%fPSA, [-2]proPSA and \% [-2]proPSA and PHIdensity (AUC 0.616) are not displayed within Figure 1 in order to allow a better overview of relevant variables. The power of differentiation between pT stages $(<$ pT3 and $\geq$ pT3) ( < pT3 in $326(74.6 \%)$ and $\geq$ pT3 in $111(25.4 \%)$ patients) based on the calculated AUC is presented through Table 2 and Figure 2. The variables PHI, PSA, \%fPSA and [-2]proPSA and further PHI- and PSA-density were able to differentiate significantly $(p<0.05)$ between $<$ pT3 and $\geq$ pT3 stage. PHI always performed as the most powerful parameter with an AUC of almost 0.7. Consequently, ROC curves of insignificant parameters have been excluded for a better figure overview. For BCR prediction and differentiation between patients with and without PSA relapse, the ROC-analysis with AUC was also listed in Table 2 and Figure 3, respectively. Concerning the earliest event of BCR, PHI, PSA, [-2]proPSA and similarly PHIand PSA-density could perform as reliable predictors. Thus, PHI appears consistently in all tested models (Gleason score, pT stage) and currently also in BCR prediction as the strongest parameter. The PHI median of 46.4 provided 10 year BCR-free survival rate of $85.5 \%$ below the median and a comparable BCR-free survival rate of $67.7 \%$ above our cutoff.

\section{Comparison of PHI to established pre- and postoperative outcome parameters}

The univariate and multivariate logistic regression model of available preoperative variables as PSA, PHI (continuously coded), PHI median, TRUS volume, age and biopsy Gleason score predicting pathological stage 
Table 5: Univariate and multivariable Cox-proprotional Hazard model of postoperative variables predicting biochemical recurrence following radical prostatectomy

\begin{tabular}{|c|c|c|c|c|c|c|}
\hline \multirow{2}{*}{ Variable } & \multicolumn{3}{|c|}{ Univariate analyses } & \multicolumn{3}{|c|}{ Multivariable analyses } \\
\hline & HR & $95 \% \mathrm{CI}$ & $p$-value & HR & $95 \% \mathrm{CI}$ & $p$-value \\
\hline PSA, ng/mL (continuous) & 1.051 & $1.02-1.08$ & 0.001 & $\mathrm{n} / \mathrm{a}$ & & \\
\hline PHI (continuous) & 1.007 & $1.003-1.011$ & $<0.001$ & $\mathrm{n} / \mathrm{a}$ & & \\
\hline $\begin{array}{l}\text { PHI } \\
>\text { median vs }<\text { median }\end{array}$ & 1.83 & $1.16-2.89$ & 0.009 & 1.57 & $0.98-2.49$ & 0.060 \\
\hline $\begin{array}{l}\text { Pathological stage } \\
\geq \mathrm{pT} 3 \mathrm{a} \text { vs }<\mathrm{pT} 3 \mathrm{a}\end{array}$ & 2.76 & $1.76-4.31$ & $<0.0001$ & 1.76 & $1.11-2.80$ & 0.017 \\
\hline Margin status R1 vs R0 & 2.55 & $1.63-3.99$ & $<0.0001$ & 1.50 & $0.92-2.44$ & 0.101 \\
\hline Age, yrs (continuous) & 1.03 & $0.99-1.07$ & 0.167 & $\mathrm{n} / \mathrm{a}$ & & \\
\hline $\begin{array}{l}\text { Pathological Gleason Score } \\
<7 \text { (ISUP grade } 1) \\
=7(\text { ISUP grade } 2 \text { and } 3) \\
>7(\text { ISUP grade } \geq 4)\end{array}$ & $\begin{array}{l}\text { Ref } \\
2.06 \\
5.40\end{array}$ & $\begin{array}{c}1.15-3.67 \\
2.91-10.13\end{array}$ & $\begin{array}{c}0.015 \\
<0.0001\end{array}$ & $\begin{array}{l}\text { Ref } \\
1.92 \\
3.73\end{array}$ & $\begin{array}{l}1.09-3.40 \\
1.94-7.14\end{array}$ & $\begin{aligned} & 0.025 \\
< & 0.0001\end{aligned}$ \\
\hline
\end{tabular}

Abbreviations: PSA - prostate-specific antigen; PHI - prostate health index; pT - pathological tumor stage; TRUS - transrectal ultrasound; CI - confidence interval; HR - hazard ratio; CI - confidence interval.

$>$ pT2 were summarized in Table 3. Even though the performance of PHI using a cutoff value of 46.4 was inferior to the biopsy Gleason score, an odds ratio of $2.86(p<0.00001)$ for the univariate and $2.20(p=0.001)$ for the multivariate approach was significantly higher in comparison to all other parameters.

The results of logistic regression models that tested the prediction of a Gleason score $>6$ (ISUP grade $\geq 2$ ) are shown in Table 4. The performance of PHI was superior in comparison to all other parameters including clinical stages with consecutively higher odds ratios of 2.46 and 2.09 .

Table 5 reflects the findings of the univariate and multivariate Cox-regression of postoperative variables predicting biochemical recurrence. PHI showed substantial results with a hazard ratio of 1.83 within the univariate approach and 1.57 for the multivariate analysis, respectively. Controversially PHI showed an inferior performance to established parameters such as Gleason score, $\mathrm{T}$ stage, margin status or PSA.

\section{DISCUSSION}

In our final cohort with available 437 patients (95\% of 460 operated men) and complete follow up after RP from 2001 to 2014 we first represent PHI as a prognostic biomarker based on long term data. While most patients develop a BCR within the first two years, some have a recurrence of up to five years after RP [25]. We believe that a sufficient prediction regarding a possible BCR can only be made after a median follow up of at least 5 years because the number of BCR cases in the years 5 to 10 after RP are relatively low and decreasing continuously [25]. The data of this study supports this since $83.2 \%$ are recurrence free after 5 years, $78.6 \%$ after 8 years and $77.2 \%$ are recurrence free after 10 years. Only $6 \%$ of all PCa patients develop a BCR within the years 5 to 10 after
RP.

However, there is a clear need for better prognostic factors after RP to outweigh further treatment options like radiation or even hormonal treatment because not all patients with adverse pathology do develop a BCR. Here PHI could show its clinical value with a significantly higher median of 58.6 in those 87 patients with BCR as compared with 45.0 in those 350 men without PSA relapse $(p=0.011)$. Lughezzani et al. [24] did not provide these median values seeing as their study only included 34 patients with a BCR. They proposed a very high PHI cutoff of 82 to obtain a BCR-free survival rate of $97.7 \%$ in the patients below 82 and $69.7 \%$ for those above this cutoff [24]. When using our data, a differentiation with the PHI median of 46.4 provided 10 year BCR-free survival rate of $85.5 \%$ below the median and a comparable BCR-free survival rate of $67.7 \%$ above our cutoff. The somewhat decreased percentage of patients without BCR $(85.5 \%$ vs. $97.7 \%$ ) is most likely a result of the clearly longer follow up (65 vs. 28 months) in our study. When using the median PHI value, the difference between both BCR-free survival rates is lower $(83.5 \%$ vs. $70 \%)$, which indicates that PHI is able to predict a recurrence situation. This is also evident when comparing the AUCs of all biomarkers between patients with and without BCR. Here, PHI had the largest AUC of 0.62 compared with PSA (0.59) or $\%$ fPSA (0.56). Furthermore, PHI could also best separate between Gleason $<7$ and Gleason $\geq 7$ (ISUP grade 1 and $\geq 2$ ) with an AUC of 0.65 compared with PSA (0.58) and percent free PSA (0.51). This confirms the ability of PHI to predict tumor aggressiveness in pathological prostatectomy specimen, as already published before [19].

Accordingly, the performance of PHI within our applied logistic regression models showed its power in both preoperative as well as postoperative settings. As a consequence, patients could benefit from its clinical value before receiving adjuvant treatment or unnecessary 
invasive procedures preoperatively like for example repeat biopsies as recently published concerning men with a total PSA $>10$ ng/ml [26].

In distinction to PHI, several biomarkers for an improved BCR estimation have been reviewed [23] but none of these other markers is used in a clinical routine setting. Interestingly, a biopsy-based 17-gene genomic prostate score recently predicted a BCR and also adverse pathological outcome in men with low- and intermediaterisk PCa [27]. However, the likelihood for PHI as a routine serum parameter to become an additional tool for long term prediction seems to be much higher than for experimental marker. Particularly, PHI outperformed PCA 3 and the inclusion in Epstein and PRIAS protocols could show its substantial contribution to prediction of insignificant cancer and better selection of active surveillance candidates [28].

While Lughezzani et al. [24] used the traditional Hybritech calibration for PSA and fPSA to obtain their PHI values, our PSA and PPSA measurements were all performed using the WHO calibration that provides about 20-25\% lower PSA values [29]. The differences in PHI however were almost negligible as seen in a study using both calibrations [30].

The PHI seems to improve the overall prediction and herewith claims its important stance in clinical decision making. Despite a positive role for PHI in PCa prediction, we acknowledge limitations to the present study. Primarily our study represents a single center analysis with a retrospective approach whereas prospective multicenter studies are desirable due to a higher impact. In addition, after a 10 year follow up the categorical data of $\mathrm{pT}$ stage ( < pT3: BCR free $83.5 \%$ vs. $\geq$ pT3: BCR free rate $60.1 \%$ ) and Gleason score (Gleason 6 (ISUP grade 1): BCR free 90.1\%, Gleason 7 (ISUP grade 2 and 3): BCR free $76 \%$ and Gleason $\geq 8$ (ISUP grade $\geq 4$ ): BCR free rate $47.4 \%)$ showed larger differences than PHI $(85.5 \%$ vs. $67.7 \%$ ), which indicates that PHI independently should not be used as predictor. We are aware that time dependent functions (especially survival outcomes) can be displayed by Kaplan-Meier curves. While survival was not the primary endpoint but BCR, the AUC represents a reliable estimate. Since lymphadenectomy was only performed in 267 patients, the lymph node status was only applicable in $61.1 \%$. A median of 14 lymph nodes were taken and positive lymph nodes were reported only in $5(1.87 \%)$ patients. Consequently no analysis of the role of lymphadenectomy for BCR within our cohort was performed. A current important review from the EAU prostate cancer panel obtaining 66 studies with a total of 275269 patients analyzed the benefits and harms of the different extents of lymph node dissection. Meaning lymph node removal enables accurate assessment of cancer spread but may not have any direct benefit on cancer outcomes [31].

Calibration plots and decision curve analysis have not been included in our analysis, as once requested by Nguyen and Kattan in order to identify the true clinical value of a given marker as the ultimate goal [32]. But Nguyen and Kattan also requested follow-up studies involving long-term use of a marker in a multivariable analysis [32].

In conclusion, this study confirmed a clinical value for PHI in prediction of a BCR by using a multivariable approach with a median follow up of more than 5 years.

\section{MATERIALS AND METHODS}

\section{Study design and population}

A total of $460 \mathrm{PCa}$ patients with preoperative PHI measurements with WHO calibration (Beckman Coulter Access 2-Immunoassay) undergoing RP (open, laparoscopic or robot-assisted) and pelvic lymph node dissection between 2001 and 2014 at a single German tertiary center were identified. Blood was drawn and serum samples were prepared and frozen at $-80^{\circ} \mathrm{C}$ within $3 \mathrm{~h}$ of blood collection according to recommendations for pre-analytic tPSA and fPSA and p2PSA as previously published [16]. All pre-operative, operative and follow-up data were collected under an internal review board (Charité ethical committee)-approved protocol and after obtaining written informed consent from all patients. Standardized, self-administrated questionnaires were routinely sent out to all patients after 3 months and subsequently year by year after radical prostatectomy. All men were invited to complete a questionnaire consisting of the International Prostate Symptom Score (IPSS), the International Index of Erectile Function (IIEF-5), the International Consultation on Incontinence Questionnaire (ICIQ), question 29 and 30 of the European Organization for Research and Treatment of Cancer Quality of Life Questionnaire (EORTEC QLQ30) and general data about date of surgery, level and date of the last estimated prostate-specific antigen.

BCR was defined as two consecutive PSA values > 0.1 after a previous non-detectable level. Consequently, time to BCR was defined as months between surgery and $\mathrm{BCR}$ development and concerning patients without BCR, censoring was performed at the time of last follow-up. All patients with preoperative anti-androgen therapy and with persisting PSA levels after RP were excluded from the analysis. Data on recurrences and survival was obtained via telephone interviews and standardized questionnaires.

\section{Statistical analysis}

Differences between patients with and without BCR were compared using the chi-square (Fisher's exact) test for categorical variables and the Mann Whitney U-Test for continuous variables. Gleason score, pathological 
tumor stage, and surgical margin status, were considered as categorical variables. PHI, Age and PSA were regarded as continuous variables. The power of prediction was analyzed multivariate adjusted logistic and Cox regression. All statistical calculations were two-sided unless stated otherwise and performed using SPSS v.23 (IBM Corp, Somers, NY, USA). A $p$-value $<0.05$ was considered statistically significant.

\section{Abbreviations}

PSA-prostate-specific antigen; PCa-prostate cancer; fPSA-free prostate-specific antigen; PHI-prostate health index; \%fPSA-percent free prostate-specific antigen; RP-radical prostatectomy; ISUP-international society of urological pathology; BCR-biochemical recurrence; pT-pathological tumor stage; pN-lymph node invasion; AUC-area under the curve; ROC-receiver operating curve; R-resection status

\section{Author contributions}

All authors have made a significant contribution to the findings and methods in the paper and all authors have read and approved the final draft.

Andreas Maxeiner: Conception or design of the work, Data collection, Data analysis and interpretation, Drafting the article, Critical revision of the article, Final approval of the version to be published.

Ergin Kilic: Data analysis and interpretation, Critical revision of the article, Final approval of the version to be published.

Julia Matalon: Data collection, Data analysis and interpretation, Critical revision of the article, Final approval of the version to be published.

Frank Friedersdorff: Data analysis and interpretation, Critical revision of the article, Final approval of the version to be published.

Kurt Miller: Data analysis and interpretation, Critical revision of the article, Final approval of the version to be published.

Klaus Jung: Data analysis and interpretation, Critical revision of the article, Final approval of the version to be published.

Carsten Stephan: Data collection, Data analysis and interpretation, Critical revision of the article, Final approval of the version to be published.

Jonas Busch: Conception or design of the work, Data analysis and interpretation, Critical revision of the article, Final approval of the version to be published.

\section{ACKNOWLEDGMENTS}

We would like to acknowledge the excellent work of Markus Loos on the Charité prostate cancer database.
We cordially thank Gunilla Maxeiner for carefully reading the manuscript.

\section{CONFLICTS OF INTEREST}

None of the contributing authors have any conflict of interest, including specific financial interests or relationships and affiliations relevant to the subject matter or materials discussed in the manuscript.

\section{FUNDING}

This research received no specific grant from any funding agency in the public, commercial, or not-for-profit sectors. This statement counts for all listed authors.

\section{REFERENCES}

1. Lilja H, Christensson A, Dahlen U, Matikainen MT, Nilsson O, Pettersson K, Lovgren T. Prostate-specific antigen in serum occurs predominantly in complex with alpha 1-antichymotrypsin. Clinical chemistry. 1991; 37: 16181625 .

2. Stenman UH, Leinonen J, Alfthan H, Rannikko S, Tuhkanen K, Alfthan O. A complex between prostatespecific antigen and alpha 1-antichymotrypsin is the major form of prostate-specific antigen in serum of patients with prostatic cancer: assay of the complex improves clinical sensitivity for cancer. Cancer research. 1991; 51: 222-226.

3. Catalona WJ, Partin AW, Slawin KM, Brawer MK, Flanigan RC, Patel A, Richie JP, deKernion JB, Walsh PC, Scardino PT, Lange PH, Subong EN, Parson RE, et al. Use of the percentage of free prostate-specific antigen to enhance differentiation of prostate cancer from benign prostatic disease: a prospective multicenter clinical trial. Jama. 1998; 279: 1542-1547.

4. Mikolajczyk SD, Grauer LS, Millar LS, Hill TM, Kumar A, Rittenhouse HG, Wolfert RL, Saedi MS. A precursor form of PSA (pPSA) is a component of the free PSA in prostate cancer serum. Urology. 1997; 50: 710-714.

5. Mikolajczyk SD, Marks LS, Partin AW, Rittenhouse HG. Free prostate-specific antigen in serum is becoming more complex. Urology. 2002; 59: 797-802.

6. Mikolajczyk SD, Millar LS, Wang TJ, Rittenhouse HG, Marks LS, Song W, Wheeler TM, Slawin KM. A precursor form of prostate-specific antigen is more highly elevated in prostate cancer compared with benign transition zone prostate tissue. Cancer research. 2000; 60: 756-759.

7. Catalona WJ, Bartsch G, Rittenhouse HG, Evans CL, Linton HJ, Amirkhan A, Horninger W, Klocker H, Mikolajczyk SD. Serum pro prostate specific antigen improves cancer detection compared to free and complexed prostate specific antigen in men with prostate specific antigen 2 to $4 \mathrm{ng} / \mathrm{ml}$. The Journal of urology. 2003; 170: 2181-2185. 
8. Catalona WJ, Bartsch G, Rittenhouse HG, Evans CL, Linton HJ, Horninger W, Klocker H, Mikolajczyk SD. Serum proprostate specific antigen preferentially detects aggressive prostate cancers in men with 2 to $4 \mathrm{ng} / \mathrm{ml}$ prostate specific antigen. The Journal of urology. 2004; 171: 2239-2244.

9. Sokoll LJ, Wang Y, Feng Z, Kagan J, Partin AW, Sanda MG, Thompson IM, Chan DW. [-2]proenzyme prostate specific antigen for prostate cancer detection: a national cancer institute early detection research network validation study. The Journal of urology. 2008; 180: 539-543.

10. Stephan C, Kahrs AM, Cammann H, Lein M, Schrader M, Deger S, Miller K, Jung K. A [-2]proPSA-based artificial neural network significantly improves differentiation between prostate cancer and benign prostatic diseases. The Prostate. 2009; 69: 198-207.

11. Jansen FH, van Schaik RH, Kurstjens J, Horninger W, Klocker H, Bektic J, Wildhagen MF, Roobol MJ, Bangma $\mathrm{CH}$, Bartsch G. Prostate-specific antigen (PSA) isoform p2PSA in combination with total PSA and free PSA improves diagnostic accuracy in prostate cancer detection. European urology. 2010; 57: 921-927.

12. Le BV, Griffin CR, Loeb S, Carvalhal GF, Kan D, Baumann NA, Catalona WJ. [-2]Proenzyme prostate specific antigen is more accurate than total and free prostate specific antigen in differentiating prostate cancer from benign disease in a prospective prostate cancer screening study. The Journal of urology. 2010; 183: 1355-1359.

13. Catalona WJ, Partin AW, Sanda MG, Wei JT, Klee GG, Bangma CH, Slawin KM, Marks LS, Loeb S, Broyles DL, Shin SS, Cruz AB, Chan DW, et al. A multicenter study of [-2]pro-prostate specific antigen combined with prostate specific antigen and free prostate specific antigen for prostate cancer detection in the 2.0 to $10.0 \mathrm{ng} / \mathrm{ml}$ prostate specific antigen range. The Journal of urology. 2011; 185: 1650-1655.

14. Lazzeri M, Haese A, de la Taille A, Palou Redorta J, McNicholas T, Lughezzani G, Scattoni V, Bini V, Freschi M, Sussman A, Ghaleh B, Le Corvoisier P, Alberola Bou $\mathrm{J}$, et al. Serum isoform [-2]proPSA derivatives significantly improve prediction of prostate cancer at initial biopsy in a total PSA range of 2-10 ng/ml: a multicentric European study. European urology. 2013; 63: 986-994.

15. Sokoll LJ, Sanda MG, Feng Z, Kagan J, Mizrahi IA, Broyles DL, Partin AW, Srivastava S, Thompson IM, Wei JT, Zhang Z, Chan DW. A prospective, multicenter, National Cancer Institute Early Detection Research Network study of [-2]proPSA: improving prostate cancer detection and correlating with cancer aggressiveness. Cancer epidemiology, biomarkers \& prevention. 2010; 19: 1193-1200.

16. Stephan C, Vincendeau S, Houlgatte A, Cammann H, Jung $\mathrm{K}$, Semjonow A. Multicenter evaluation of [-2]proprostatespecific antigen and the prostate health index for detecting prostate cancer. Clinical chemistry. 2013; 59: 306-314.

17. Filella X, Gimenez N. Evaluation of [-2] proPSA and
Prostate Health Index (phi) for the detection of prostate cancer: a systematic review and meta-analysis. Clinical chemistry and laboratory medicine. 2013; 51: 729-739.

18. Guazzoni G, Lazzeri M, Nava L, Lughezzani G, Larcher A, Scattoni V, Gadda GM, Bini V, Cestari A, Buffi NM, Freschi M, Rigatti P, Montorsi F. Preoperative prostatespecific antigen isoform p2PSA and its derivatives, $\%$ p2PSA and prostate health index, predict pathologic outcomes in patients undergoing radical prostatectomy for prostate cancer. European urology. 2012; 61: 455-466.

19. Fossati N, Buffi NM, Haese A, Stephan C, Larcher A, McNicholas T, de la Taille A, Freschi M, Lughezzani G, Abrate A, Bini V, Palou Redorta J, Graefen M, et al. Preoperative Prostate-specific Antigen Isoform p2PSA and Its Derivatives, \%p2PSA and Prostate Health Index, Predict Pathologic Outcomes in Patients Undergoing Radical Prostatectomy for Prostate Cancer: Results from a Multicentric European Prospective Study. European urology. 2015; 68: 132-138.

20. Lughezzani G, Briganti A, Karakiewicz PI, Kattan MW, Montorsi F, Shariat SF, Vickers AJ. Predictive and prognostic models in radical prostatectomy candidates: a critical analysis of the literature. European urology. 2010; 58: 687-700.

21. Abdollah F, Karnes RJ, Suardi N, Cozzarini C, Gandaglia G, Fossati N, Vizziello D, Sun M, Karakiewicz PI, Menon M, Montorsi F, Briganti A. Impact of adjuvant radiotherapy on survival of patients with node-positive prostate cancer. Journal of clinical oncology. 2014; 32: 3939-3947.

22. Thompson IM, Valicenti RK, Albertsen P, Davis BJ, Goldenberg SL, Hahn C, Klein E, Michalski J, Roach M, Sartor O, Wolf JS Jr, Faraday MM. Adjuvant and salvage radiotherapy after prostatectomy: AUA/ASTRO Guideline. The Journal of urology. 2013; 190: 441-449.

23. Miyake H, Fujisawa M. Prognostic prediction following radical prostatectomy for prostate cancer using conventional as well as molecular biological approaches. International journal of urology. 2013; 20: 301-311.

24. Lughezzani G, Lazzeri M, Buffi NM, Abrate A, Mistretta FA, Hurle R, Pasini L, Castaldo L, Zandegiacomo De Zorzi S, Peschechera R, Fiorini G, Taverna G, Casale P, et al. Preoperative prostate health index is an independent predictor of early biochemical recurrence after radical prostatectomy: Results from a prospective single-center study. Urologic oncology. 2015; 33: 337-314.

25. Hu XH, Cammann H, Meyer HA, Jung K, Lu HB, Leva N, Magheli A, Stephan C, Busch J. Risk prediction models for biochemical recurrence after radical prostatectomy using prostate-specific antigen and Gleason score. Asian journal of andrology. 2014; 16: 897-901.

26. Lazzeri M, Lughezzani G, Haese A, McNicholas T, de la Taille A, Buffi NM, Cardone P, Hurle R, Casale P, Bini V, Redorta JP, Graefen M, Guazzoni G. Clinical performance of prostate health index in men with tPSA $>10 \mathrm{ng} / \mathrm{ml}$ : Results from a multicentric European study. Urologic oncology. 
2016; 34: 413-419.

27. Cullen J, Rosner IL, Brand TC, Zhang N, Tsiatis AC, Moncur J, Ali A, Chen Y, Knezevic D, Maddala T, Lawrence HJ, Febbo PG, Srivastava S, et al. A Biopsybased 17-gene Genomic Prostate Score Predicts Recurrence After Radical Prostatectomy and Adverse Surgical Pathology in a Racially Diverse Population of Men with Clinically Low- and Intermediate-risk Prostate Cancer. European urology. 2015; 68: 123-131.

28. Cantiello F, Russo GI, Cicione A, Ferro M, Cimino S, Favilla V, Perdona S, De Cobelli O, Magno C, Morgia G, Damiano R. PHI and PCA3 improve the prognostic performance of PRIAS and Epstein criteria in predicting insignificant prostate cancer in men eligible for active surveillance. World journal of urology. 2016; 34: 485-493.

29. Stephan C, Bangma C, Vignati G, Bartsch G, Lein M, Jung K, Philippe M, Semjonow A, Catalona WJ. 20-25\% lower concentrations of total and free prostate-specific antigen (PSA) after calibration of PSA assays to the WHO reference materials--analysis of 1098 patients in four centers. The International journal of biological markers. 2009; 24: 65-69.
30. Loeb S, Sokoll LJ, Broyles DL, Bangma CH, van Schaik RH, Klee GG, Wei JT, Sanda MG, Partin AW, Slawin KM, Marks LS, Mizrahi IA, Shin SS, et al. Prospective multicenter evaluation of the Beckman Coulter Prostate Health Index using WHO calibration. The Journal of urology. 2013; 189: 1702-1706.

31. Fossati N, Willemse PM, Van den Broeck T, van den Bergh RC, Yuan CY, Briers E, Bellmunt J, Bolla M, Cornford P, De Santis M, MacPepple E, Henry AM, Mason MD, et al. The Benefits and Harms of Different Extents of Lymph Node Dissection During Radical Prostatectomy for Prostate Cancer: A Systematic Review. European urology. 2017 Jan 24. doi: 10.1016/j.eururo.2016.12.003. [Epub ahead of print].

32. Nguyen CT, Kattan MW. How to tell if a new marker improves prediction. European urology. 2011; 60: 226-228. 